\title{
Spinocerebellar ataxia 28: a novel AFG3L2 mutation in a German family with young onset, slow progression and saccadic slowing
}

Christine Zühlke ${ }^{1 \dagger}$, Barbara Mikat $^{2 \dagger}$, Dagmar Timmann ${ }^{3}$, Dagmar Wieczorek ${ }^{2}$, Gabriele Gillessen-Kaesbach ${ }^{1}$ and Katrin Bürk ${ }^{4,5^{*}}$

\begin{abstract}
Background: Spinocerebellar ataxia type 28 (SCA28) is related to mutations of the ATPase family gene 3-like 2 gene (AFG3L2). To date, 13 private missense mutations have been identified in families of French, Italian, and German ancestry, but overall, the disorder seems to be rare in Europe. Here, we report a kindred of German ancestry with four affected family members presenting with slowly progressive ataxia, mild pyramidal tract signs and slow saccades.

Methods: After excluding repeat expansions in the genes for SCA1-3, 6-8, 10, 12, and 17, Sanger sequencing of the coding regions of TTBK2 (SCA11), KCNC3 (SCA13), PRKCG (SCA14), FGF14 (SCA27) and AFG3L2 (SCA28) was performed. The 17 coding exons of AFG3L2 with flanking intronic sequences were amplified by PCR and sequenced on both strands.

Results: Sequencing detected a novel potential missense mutation (p.Y689N) in the C-terminal proteolytic domain, the mutational hotspot of AFG3L2. The online programme "PolyPhen-2" classifies this amino acid exchange as probably damaging (score 0.990). Similarly to most of the published SCA28 mutations, the novel mutation is located within exon 16. Mutations in exon 16 alter the proteolytic activity of the protease AFG3L2 that is highly expressed in Purkinje cells.
\end{abstract}

Conclusions: Genetic testing should be considered in dominant ataxia with pyramidal tract signs and saccadic slowing.

Keywords: AFG3L2, Spinocerebellar ataxia, Slow saccades

\section{Background}

The spinocerebellar ataxias (SCAs) represent a clinically and genetically heterogeneous group of inherited neurological disorders with overlapping as well as highly variable phenotypes characterised by progressive incoordination, dysarthria and impaired eye movements. To date, more than 30 genetic loci have been described [1]. Mutations have been isolated in 20 genes, so far. Ten SCAs are caused

\footnotetext{
* Correspondence: buerk@med.uni-marburg.de

${ }^{\dagger}$ Equal contributors

${ }^{4}$ Department of Neurology, Philipps University of Marburg, Baldinger straße, 53043 Marburg, Germany

${ }^{5}$ Paracelsus-Elena Klinik, Kassel, Germany

Full list of author information is available at the end of the article
}

by repeat expansions while deletions, missense, nonsense or frame shift mutations have been identified in the remaining genes. The genetic locus for SCA28 had been mapped to chromosome 18 in 2006 [2]. Meanwhile, 13 missense mutations of the ATPase family gene 3-like 2 gene (AFG3L2) have been reported to cause ataxia [3-7]. In addition, homozygous AFG3L2 mutations were identified in a spastic ataxianeuropathy syndrome [8]. Here, we describe a family of German ancestry carrying a novel AFG3L2 mutation.

\section{Results and discussion \\ Clinical findings}

Onset was subtle with first symptoms not always indicative for hereditary cerebellar ataxia: the 81 year old 
mother first noticed bilateral ptosis at the age of 55 that worsened over time and required blepharoplastic surgery. Patient 3 suffers from epilepsy with infrequent seizures since adolescence.

Progression was usually slow with most patients remaining ambulatory several decades after onset. Saccadic slowing developed over time. For further clinical details, see Table 1. MRI studies yielded isolated cerebellar atrophy with intact brain stem and cortical structures. In two patients, there was evidence for additional small-sized white matter lesions on T2 weighted MRI images that could not be explained by vascular or inflammatory disease. Electrophysiological studies in patient 3 yielded normal motor and sensory nerve conduction velocities and amplitudes (peroneal, tibial and sural nerve).

\section{Molecular genetic analysis}

Sequencing revealed the heterozygous mutation c. $2065 \mathrm{~T}>\mathrm{A}$ in exon 16 of the $A F G 3 L 2$ gene in all affected family members. The mutation segregated with the disease. On the amino acid level, this substitution results in the missense exchange p.Y689N.

\section{Discussion}

The clinical presentation in this kindred is highly compatible with the SCA28 phenotype with a slowly progressive cerebellar syndrome, hyperreflexia in the lower

Table 1 Clinical features

\begin{tabular}{|c|c|c|c|c|}
\hline & Patient 1 & Patient 2 & Patient 3 & Patient 4 \\
\hline Sex & $\mathrm{F}$ & M & $\mathrm{F}$ & M \\
\hline Age & 81 & 61 & 59 & 53 \\
\hline Age of onset andFirst symptoms & $\begin{array}{l}55 \text { ptosis + falls } 60 \text { gait } \\
\text { disturbance }\end{array}$ & 24 gait disturbance & 16 seizures39 gait disorder & $\begin{array}{l}\text { no } \\
\text { subjectivecomplaints }\end{array}$ \\
\hline Walking assistance (age) & 65 & 60 & 50 & - \\
\hline $\begin{array}{l}\text { Disease duration (from onset of gait } \\
\text { disorder to physical examination) }\end{array}$ & 36 & 37 & 20 & $?$ \\
\hline MRI & $\mathrm{Nd}$ & $\begin{array}{l}\text { Cerebellar atrophyDiscrete } \\
\text { white matter lesions(age 56) }\end{array}$ & $\begin{array}{l}\text { Cerebellar atrophyDiscrete } \\
\text { white matter lesions(age 56) }\end{array}$ & $\mathrm{Nd}$ \\
\hline Ataxia of stance and gait & +++ & ++ & ++ & + \\
\hline Upper limb ataxia & + & + & + & + \\
\hline Lower limb ataxia & + & + & + & + \\
\hline Intention tremor & - & - & - & - \\
\hline Dysarthria & $(+)$ & ++ & + & + \\
\hline Impaired smooth pursuit & $\begin{array}{l}\text { Cannot be evaluated due } \\
\text { to limitation of gaze }\end{array}$ & + & - & + \\
\hline Gaze evoked nystagmus horizontal & $\begin{array}{l}\text { Cannot be evaluated due } \\
\text { to limitation of gaze }\end{array}$ & + & - & + \\
\hline $\begin{array}{l}\text { Impaired suppression of the } \\
\text { vestibuloocular reflex (VOR) }\end{array}$ & - & - & + & - \\
\hline Limitation of gaze & $\begin{array}{l}\text { Vertical completeHorizontal } \\
\text { incomplete }\end{array}$ & - & - & - \\
\hline Saccadic slowing & ++ & - & ++ & - \\
\hline Ptosis & +++ & - & - & - \\
\hline VI paresis & - & - & bilateral & - \\
\hline Dysphagia & - & + & - & - \\
\hline Hearing loss & + & - & - & - \\
\hline Deep tendon reflexes & brisk & brisk & increased & brisk \\
\hline Extensor plantar responses & - & - & - & - \\
\hline Spasticity & - & - & - & - \\
\hline Impaired noci- and thermoception & - & - & + & + \\
\hline Impaired vibration sense & + & + & + & + \\
\hline Other symptoms & - & sleep apnea & rare seizures & - \\
\hline SARA score [15] & $11 / 40$ & $11 / 40$ & $19 / 40$ & $8 / 40$ \\
\hline
\end{tabular}


limbs (76\%) and saccadic slowing (50\%) [3, 4]. Saccadic slowing has been considered a typical clinical feature in SCA2 while pyramidal tract signs are usually absent $[9,10]$. Regarding the small sample size, further studies will be necessary to corroborate the combination of slow saccades and pyramidal tract signs as core features of SCA28. Based on these findings, we have actually suspected SCA28 in an individual with early onset and slowly progressive ataxia, saccadic slowing and pyramidal tract signs. Despite a negative family history, molecular genetic testing has actually revealed a SCA28 mutation described earlier by Di Bella and coworkers [5]. Other less characteristic features include ptosis $(48 \%)$ and impaired proprioception $(45 \%)[3,6]$. Behavioural abnormalities and cognitive impairment have been observed in some patients. SCA28 symptoms usually start in early adulthood (mean 39 years, SD 13) with a wide range from 3 to 60 years. Actually, the age of onset seems to depend on the individual mutation $[3,4,6]$.

The AFG3L2 gene, mutated in SCA28, is composed of 17 exons coding for a protein of 797 amino acids with different functional domains: an AAA consensus sequence together with an ATP/GTP-binding site, a peptidase M41 domain containing the HEXXH motif which is a characteristic feature of a zinc-dependent binding domain, and a RNA-binding region [11]. AFG3L2 is highly homologous to paraplegin, the product of the SPG7 gene. Mutations in the SPG7 gene are responsible for a subtype of hereditary spastic paraplegia (HSP) [12]. Both, AFG3L2 as well as paraplegin are metalloproteases of the AAAsuperfamily; as components of the two mitochondrial AAA (m-AAA) protease isoenzymes in the inner mitochondrial membrane they are involved in the degradation of non-assembled membrane proteins as well as in the activation of mitochondrial proteins [13]. Notably, 12 of 13 published SCA28 mutations correspond to missense exchanges with 11 mutations being located within exon 16 which contributes to the peptidase M41 domain [4-7]. They alter the proteolytic activity of the protease AFG3L2 that is highly expressed in Purkinje cells [5]. The resulting mitochondrial impairment might account for the clinical similarities of SCSA28 and SPG7 with mitochondrial disorders. Two or even three different mutations affecting amino acids at positions 666, 671, and 689 have been identified in SCA28 patients to date. The variation p.Y689N (c.2065T>A) present in our family, is not listed in the integrated map of genetic variation from 1092 human genomes (1000genomes.org). Interestingly, another mutation affecting the tyrosine residue at position 698 (p.Y689H) has recently been identified in another SCA28 patient [7].

\section{Conclusion}

Based on these findings, the missense mutation p.Y689N is likely to have a pathogenic impact on the SCA28 phenotype. This assumption is supported by the strong conservation of tyrosine $(\mathrm{Y})$ at position 689 e.g. in monkey, mouse, dog, elephant, opossum, chicken and zebrafish (UCSC Genome Browser, hg19). Furthermore, the online programme "PolyPhen-2" classifies this amino acid exchange as probably damaging (score 0.990).

\section{Methods}

\section{Subjects}

Clinical data and blood samples were obtained in four affected individuals (mother: patient 1 , three of four children: patients 2 to 4 , details see Table 1 ) and one unaffected sibling (57 years at examination, SARA score 0/ 40 , personally examined by DT). The study was approved by the Institutional review board of University of Lübeck.

\section{Genetic analysis}

After having obtained informed consent, genomic DNA was extracted from peripheral blood leukocytes by standard protocols. According to the EFNS guidelines [14] prior to sequence analysis, expansions at the loci for SCA1, 2, 3, 6, 7, 8, 10, 12, and 17 were excluded. Additional Sanger sequencing of the coding regions of TTBK2 (SCA11), KCNC3 (SCA13), PRKCG (SCA14), and FGF14 (SCA27) identified only known polymorphisms and SNPs. For AFG3L2, the 17 coding exons with flanking intronic sequences were also amplified by PCR and sequenced on both strands. Pathogenic mutations in SPTBN2 (SCA5), KCND3 (SCA19/22), PDYN (SCA23), and ITPR1 (SCA29) genes have not tested in this kindred but a pathogenic impact appears less likely for one of these genes with respect to phenotype characteristics and geographical restrictions (at least in some of these genotypes).

\section{Data bases}

Ensembl AFG3L2 ENSG00000141385, transcript ENST00000269143. HGMD biobase: www.hgmd.cf.ac.uk; UCSC genome browser: http://genome.ucsc.edu; 1000 genomes: www.1000genomes.org; PolyPhen-2-prediction of functional effects of human nsSNPs: http:// genetics.bwh.harvard.edu/pph2/.

\section{Competing interests}

The authors declare no conflicts of interest.

\section{Authors' contributions}

CZ, BM and GG carried out the molecular genetic studies and helped to draft the manuscript. DT and DW performed clinical examinations and helped to draft the manuscript. $\mathrm{KB}$ and $\mathrm{CZ}$ participated in the design of the study. KB, performed the clinical examinations and drafted the manuscript. All authors read and approved the final manuscript. 


\section{Acknowledgements}

We thank the patients and their family for supplying blood samples for scientific research.

\section{Author details}

'Institute of Human Genetics, University of Lübeck, Lübeck, Germany.

${ }^{2}$ Institute of Human Genetics, University of Duisburg-Essen, Essen, Germany. ${ }^{3}$ Department of Neurology, University of Essen, Essen, Germany. ${ }^{4}$ Department of Neurology, Philipps University of Marburg, Baldinger straße, 53043 Marburg, Germany. ${ }^{5}$ Paracelsus-Elena Klinik, Kassel, Germany.

Received: 2 December 2015 Accepted: 3 December 2015

Published online: 16 December 2015

\section{References}

1. Matilla-Duenas A, Sanchez I, Corral-Juan M, Davalos A, Alvarez R, Latorre $P$. Cellular and molecular pathways triggering neurodegeneration in the spinocerebellar ataxias. Cerebellum. 2010;9:148-66. doi:10.1007/s12311009-0144-2.

2. Cagnoli C, Mariotti C, Taroni F, Seri M, Brussino A, Michielotto C, et al. SCA28, a novel form of autosomal dominant cerebellar ataxia on chromosome 18p11.22-q11.2. Brain. 2006;129:235-42. doi:10.1093/brain/ awh651.

3. Mariotti C, Brusco A, Di Bella D, Cagnoli C, Seri M, Gellera C, et al. Spinocerebellar ataxia type 28: a novel autosomal dominant cerebellar ataxia characterized by slow progression and ophthalmoparesis. Cerebellum. 2008;7:184-8. doi:10.1007/s12311-008-0053-9.

4. Edener U, Wollner J, Hehr U, Kohl Z, Schilling S, Kreuz F, et al. Early onset and slow progression of SCA28, a rare dominant ataxia in a large fourgeneration family with a novel AFG3L2 mutation. Eur J Hum Genet. 2010;18: 965-8. doi:10.1038/ejhg.2010.40.

5. Di Bella D, Lazzaro F, Brusco A, Plumari M, Battaglia G, Pastore A, et al. Mutations in the mitochondrial protease gene AFG3L2 cause dominant hereditary ataxia SCA28. Nat Genet. 2010;42:313-21. doi:10.1038/ng.544.

6. Cagnoli C, Stevanin G, Brussino A, Barberis M, Mancini C, Margolis RL, et al. Missense mutations in the AFG3L2 proteolytic domain account for approximately $1.5 \%$ of European autosomal dominant cerebellar ataxias. Hum Mutat. 2010;31:1117-24. doi:10.1002/humu.21342.

7. Lobbe AM, Kang JS, Hilker R, Hackstein H, Muller U, Nolte D. A novel missense mutation in AFG3L2 associated with late onset and slow progression of spinocerebellar ataxia type 28. J Mol Neurosci. 2014;52:493-6. doi:10.1007/s12031-013-0187-1.

8. Pierson TM, Adams D, Bonn F, Martinelli P, Cherukuri PF, Teer JK, et al. Whole-exome sequencing identifies homozygous AFG3L2 mutations in a spastic ataxia-neuropathy syndrome linked to mitochondrial m-AAA proteases. PLoS Genet. 2011;7, e1002325. doi:10.1371/journal.pgen.1002325.

9. Wadia N, Pang J, Desai J, Mankodi A, Desai M, Chamberlain S. A clinicogenetic analysis of six Indian spinocerebellar ataxia (SCA2) pedigrees. The significance of slow saccades in diagnosis. Brain. 1998; 121(Pt 12):2341-55.

10. Yokota T, Sasaki H, Iwabuchi K, Shiojiri T, Yoshino A, Otagiri A, et al. Electrophysiological features of central motor conduction in spinocerebellar atrophy type 1, type 2, and Machado-Joseph disease. J Neurol Neurosurg Psychiatry. 1998;65:530-4.

11. Banfi S, Bassi MT, Andolfi G, Marchitiello A, Zanotta S, Ballabio A, et al. Identification and characterization of AFG3L2, a novel paraplegin-related gene. Genomics. 1999;59:51-8. doi:10.1006/geno.1999.5818.

12. Casari G, De Fusco M, Ciarmatori S, Zeviani M, Mora M, Fernandez P, et al. Spastic paraplegia and OXPHOS impairment caused by mutations in paraplegin, a nuclear-encoded mitochondrial metalloprotease. Cell. 1998;93: 973-83.

13. Nolden $M$, Ehses $S$, Koppen M, Bernacchia A, Rugarli El, Langer T. The m-AAA protease defective in hereditary spastic paraplegia controls ribosome assembly in mitochondria. Cell. 2005;123:277-89. doi:10.1016/j.cell.2005.08.003.

14. Gasser T, Finsterer J, Baets J, Van Broeckhoven C, Di Donato S, Fontaine B, et al. EFNS guidelines on the molecular diagnosis of ataxias and spastic paraplegias. Eur J Neurol. 2010;17:179-88. doi:10.1111/j.1468-1331.2009.02873.x.

15. Schmitz-Hubsch T, du Montcel ST, Baliko L, Berciano J, Boesch S, Depondt C, et al. Scale for the assessment and rating of ataxia: development of a new clinical scale. Neurology. 2006;66:1717-20. doi:10.1212/01.wnl.0000219042. 60538.92 .

\section{Submit your next manuscript to BioMed Central and we will help you at every step:}

- We accept pre-submission inquiries

- Our selector tool helps you to find the most relevant journal

- We provide round the clock customer support

- Convenient online submission

- Thorough peer review

- Inclusion in PubMed and all major indexing services

- Maximum visibility for your research

Submit your manuscript at www.biomedcentral.com/submit 